\title{
Characterization of Bipolaris sorokiniana and Alternaria sesami isolates obtained from sesame (Sesamum indicum L.) in Egypt
}

\author{
M. M. A. Abo-Ghazala ${ }^{1}$, A. M. M. El-Shazly ${ }^{1}$ and I. H. Tolba ${ }^{1, *}$ \\ ${ }^{1}$ Plant Pathology Branch, Agricultural Botany Department, Faculty of Agriculture, Al-Azhar University, Nasr City, \\ Cairo, Egypt \\ * Correspondence: Ibrahimshahda@azhar.edu.eg
}

\begin{abstract}
Keeping in view the losses caused by the leaf spot disease of sesame, the present study was carried out to characterize fungal pathogenic causes leaf spot disease of sesame in Egypt. During the current study, Bipolaris sorokiniana and Alternaria sesami isolates were characterized by microscopy, colony characteristic and its pathogenicity. The identities of the fungi were confirmed by analysis of rDNA ITS (internal transcribed spacer). Fourteen RAPD primers were screened with the DNA of the fungal isolates to detect the polymorphism among these isolates. The estimated genetic similarities ranged from $74 \%$ to $82 \%$ with Bipolaris isolates, and from $85 \%$ to $96 \%$ with Alternaria isolates revealing very high levels of genetic similarity among the studied accessions. Significant differences in aggressiveness among the isolates of both pathogens were observed after artificial inoculation of sesame plants using spray inoculation methods. The disease reaction of three varieties of sesame to both fungi reveled that, the variety Shandawil-3 showed the highest degree of susceptibility to both pathogens. The host range of the isolates of both pathogens were tested on 11 plant species belonged to three families. All isolates of Bipolaris sorokiniana were pathogenic on tomato, maize, broad bean, bean, sorghum and wheat. On the other hand, the isolates of Alternaria sesami markedly varied in its pathogenicity on tomato, broad bean, bean and sorghum and were nonpathogenic to other tested plant species. In conclusions from our results, the causal pathogen Bipolaris sorokiniana is considered the most prefiling pathogen among the sesame leaf spot causal pathogen in Egypt.
\end{abstract}

Keywords: Alternaria sesami; Bipolaris sorokiniana; aggressiveness; host range; rDNA ITS.

\section{INTRODUCTION}

Sesame (Sesamum indicum L.) is one of the ancient crops and considered as most important oilseed crop in tropical and subtropical areas of the world. The cultivated sesame derives from wild populations originated from the South Asia, especially the western Indian peninsula, or the Punjab and parts of Pakistan (Fuller, 2003). Sesame is attacked by several infectious plant pathogens which are responsible for major damaging factor to crop plants. Among important sesame diseases, Alternaria leaf spot is prevalent in all the sesame growing areas of the world (Verma, et al., 2005; Kolte, 1985; Bhale, et al., 1998). The Alternaria leaf spot، caused by Alternaria sesami (Kawamura) Mohanty and Behera، produces small, irregular brown spots on the leaf blade. These spots collapse each other and form elongated lesions. Same symptoms may also appear on stem and seed capsule. Due to severe infection, the plants may become defoliated completely. Species of Bipolaris (Shoemaker, 1959), are important plant pathogens associated with over 60 host genera (Sivanesan, 1987; Manamgoda, et al., 2011; Agrios, 2005).

Accurate identification and precise naming of species are crucial as the name is the key to accessing all accumulated knowledge (Cai, et al., 2009 and 2011; Hyde, et al., 2010; Hawksworth, et al., 2011; KoKo, et al., 2011; Udayanga, et al., 2011). Using molecular taxonomy, many uncertainties of conventional taxonomy can be resolved (Valente, et al., 1999; Mendoza, et al., 2001). Phylogenetic studies of Bipolaris have shown that the genus Bipolaris is not monophyletic and some Bipolaris species with short straight conidia cluster with Curvularia (Goh, 1998; Berbee, et al., 1999; Emami and Hack, 2002; Manamgoda, et al., 2011).

DNA markers have become a powerful tool to study taxonomy and molecular genetic of a variety of organisms. The random amplified polymorphic DNA (RAPD) allows quick assessment of genetic variability in various taxa, and has been used to study inter and intraspecific variability among isolates of several fungal species (Inglis, et al., 2001 and Tigano-Milani, et al., 1995a, b).

Clear understanding of the extent of variation in virulence would be helpful in developing plant cultivars with stable resistance. In this regard, several studies were carried out to analyze the aggressiveness of Bipolaris sorokiniana and Alternaria sesami among isolates collected from different agroecological zones. Controlling plant disease with the use of cultural practices and resistant varieties are considered as safest control measures. In this regard many research workers from elsewhere evaluated sesame germplasm against the Alternaria sesami for the search of resistant cultivars (Jayaramaiah et al., 1981; Shekharappa and Patil, 2001; Basavaraj et al., 2007). 
Keeping in view the losses caused by the leaf spot disease of sesame, the present study was carried out to characterize fungal pathogenic causes leaf spot disease of sesame in Egypt. Also, the aggressiveness, varietal response and host range of the both causal fungi were studied.

\section{MATERIALS AND METHODS}

\section{Sampling and pathogens isolation \\ Sample collection}

Diseased sample of sesame plant were collected from sesame plantations located in four localities that belonged to three governorates during the summer of 2016. The sampling localities were: Abou-Hommos, Hosh Isa (AlBuhayrah Governorate), Tamia (Al-Fayoum governorate) and Beni Suef (Beni Suef Governorate). Symptomatic plants were carefully investigated and the regarded samples (leaves, stem and capsules) were collected and potted in new clean plastic pages then transported to the laboratory.

\section{Isolation of the causal pathogens}

In isolation processes, the samples were washed under running tap water for 2 minutes and then excised into small pieces $(0.5 \mathrm{~cm})$. These pieces were disinfested in $0.1 \%$ Sodium hypochloride for $2 \mathrm{~min}$ then rinsed in sterilized distilled water and dried between two sterilized filter papers. The surface sterilized samples were plated onto Potato Dextrose Agar (PDA) medium and incubated at $27^{\circ} \mathrm{C}$ until the fungal growth was appeared. The resulted fungal growths were transferred to new PDA pleats and then purified using hyphal tip or single spore techniques then labeled and kept on PDA slants at $5^{\circ} \mathrm{C}$ for further studies.

\section{Identification of isolated fungi \\ Cultural and microscopic characteristics}

Cultural and microscopic characters of the obtained isolates were studied according to (Alcorn, 1983 and 1988; Sivanesan, 1987). The colony morphology (texture, colour and growth type) and microscopical features (production of conidia, conidial and conidiophore morphology and hyphal septation) were checked and recorded. Spore morphology was studied by examining the conidial spores obtained from mature pure culture of the regarded fungal isolate under low and high-power objective (10x and 40x) of microscope. Measurements of the fungal dimension in terms of length, breadth, beak length and number of septa were determined using stage and ocular micrometer. The average of length and breadth of the conidial body, beak and number and number of transverse and longitudinal septa were recorded from 25 mature conidia for each isolate. These observations were compared with those of the standard measurements given by (Simmons, 2004). The microphotographs were taken to show the spore morphology.

\section{Pathogenicity test}

The pathogenicity of the selected fungal isolates was demonstrated by artificially inoculation of sesame plants by spore suspension along with mycelial fragments obtained from 10 days old cultures of these isolates. Pure cultures of the selected isolates were grown on potato dextrose agar medium (PDA) for 10 days. The fungal suspension of each isolate was prepared by placing $20 \mathrm{~mL}$ of sterilized distilled water in the culture plate and swabbed using paint brush and the resulted suspension were completed to $100 \mathrm{ml}$. The suspension $\left(2 \times 10^{3}\right)$ of each isolate were sprayed using manual atomizer on the foliage of 1 month old healthy sesame plants which were grown on plastic pots that were potted with sterilized mix of Peat Moss and sand. In the same manner, plants of same age were sprayed with sterile water only and served as control. The treated plants were kept for 2 days in a humid plastic bag. The tested plants were observed daily and any external symptoms was recorded.

\section{Molecular studies}

For molecular identification one isolate from each of A. sesami and B. sorokiniana were chosen to confirm their identity using Internal transcribed spacer (ITS) technique (White, et al., 1990)، the investigation was carried out in the Genetics Microbial Laboratory at the Agriculture Genetic Engineering Research Institute (AGERI), Agriculture Research Center (ARC), Giza, Egypt . The details of the test as follows:

\section{DNA extraction and purification}

DNA extraction and purification were carried out according to DNeasy Kit (Qiagen). The fungal mass was grinding under liquid nitrogen to a fine powder using a mortar and pestle. The powder and liquid nitrogen were transferred to sterilized test tube and left until the liquid nitrogen was evaporated. After this step, a $400 \mu \mathrm{L}$ of buffer $\mathrm{AP} 1$ and $4 \mu \mathrm{L}$ of RNase A stock solution (10 $\mathrm{mg} / \mathrm{mL}$ ) was added to $100 \mathrm{mg}$ of ground fungal mass and vigorously vortexed. To lyses the cells, the mixture was incubated for $30 \mathrm{~min}$ at $65^{\circ} \mathrm{C}$ with inverting the tub 3 times during incubation to mix the mixture. A $130 \mu \mathrm{L}$ of buffer AP2 was added to the lysate mix and incubate for $5 \mathrm{~min}$ on ice to precipitate detergent, proteins, and polysaccharides. The lysate was applied to the QIAshredder spin column (lilac) sitting in a $2 \mathrm{~mL}$ collection tube and centrifuged for $2 \mathrm{~min}$ at 
maximum speed. The component was transferred to a new tube without disturbing the cell-debris pellet. A 1.5 volumes of buffer AP3/E were added to the cleared lysate and mixed by pipetting. A $650 \mu \mathrm{L}$ of this mixture, including any precipitate which may have formed, was applied to the DNeasy mini spin column sitting in a $2 \mathrm{~mL}$ collection tube (supplied) and centrifuged for 1 min. at $8000 \mathrm{rpm}$ and discard flow-through. The DNeasy column was placed in a new $2 \mathrm{~mL}$ collection tube (supplied) and $500 \mu \mathrm{L}$ of buffer AW was added to the DNeasy column and centrifuged for $1 \mathrm{~min}$. at $8000 \mathrm{rpm}$ and then discard flow-through and the collection tube was reused in the next step. A $500 \mu \mathrm{L}$ buffer AW was added to the DNeasy column and centrifuged for 5 min. at maximum speed to dry the membrane. The DNeasy column was transferred to a $1.5 \mathrm{~mL}$ microcentrifuge tube (not supplied) and $100 \mu \mathrm{L}$ of preheated $\left(65^{\circ} \mathrm{C}\right)$ buffer AE was pipetted directly onto the DNeasy membrane. The tube was incubated for $5 \mathrm{~min}$. at room temperature and then centrifuged for $1 \mathrm{~min}$ at $8000 \mathrm{rpm}$ to elute. Elution with $50 \mu \mathrm{L}$ (instead of $100 \mu \mathrm{L}$ ) increases the final DNA concentration in the eluate significantly.

\section{Estimation for the DNA concentration}

A $2 \mu \mathrm{L}$ of the parent's DNA samples was run on $1 \%$ agarose gel in comparison to $10 \mu \mathrm{L}$ of a DNA size marker (lambda DNA Hind III digest Phi X 174/ HaeIII digest). To estimate DNA concentration, the degree of fluorescence of the DNA sample was compared with the different bands in DNA size marker.

\section{Polymerase Chain Reaction (PCR) using ITS}

The first round of amplification was performed using universal eukaryote primers ITS1 (F 5'- TCCGTAGGTGAACCTGCGG -3') and ITS4 (R 5'TCCTCCGCTTATTG ATATGC-3') according to (White, et al., 1990).

\section{PCR components}

The PCR amplification was performed in a total volume of 50ul, containing $1 \mathrm{X}$ reaction buffer (10 $\mathrm{m} \mathrm{M}$ Tris- $\mathrm{HCl}, \mathrm{pH} 8.3$ and $50 \mathrm{~m} \mathrm{MKCl})$, $1.5 \mathrm{~m} \mathrm{M} \mathrm{MgCl}$, $1 \mathrm{U}$ Taq DNA polymerase (promega), 2.5m M dNTPs, 30 poml of each primer and $30 \mathrm{ng}$ genomic DNA.

\section{PCR condition (thermal profile)}

PCR amplification was carried out in a PerkinElmer/ Gene Amp® PCR System 9700 (PE Applied Biosystems) thermocycler. The PCR amplification conditions were as follows: an initial extended step of denaturation at $94^{\circ} \mathrm{C}$ for 5 min followed by 40 cycles of denaturation at $94^{\circ} \mathrm{C}$ for $30 \mathrm{Sec}$., primer annealing at $50^{\circ} \mathrm{C}$ for $30 \mathrm{Sec}$. and elongation at $72^{\circ} \mathrm{C}$ for $1 \mathrm{~min}$. The primer extension segment was extended to $7 \mathrm{~min}$ at $72^{\circ} \mathrm{C}$ in the final cycle.

\section{Purification of PCR Products}

Amplified products from fungal isolates were purified using EZ-10 spin column PCR products purification PCR reaction mixture was transferred to $1.5 \mathrm{~mL}$ microfuge tube and three volumes was added of binding buffer 1 after that the mixture solution was transferred to the EZ-10 column and loft room temperature for $2 \mathrm{~min}$. after that centrifuge, $750 \mu \mathrm{L}$ of wash solution was added to the column and centrifuge at $10.000 \mathrm{rpm}$ for two minutes, repeated washing, $10.000 \mathrm{rpm}$ was spine for an additional min. to remove any residual wash solution. the column was transferred into a clean $1.5 \mathrm{~mL}$ microfuge tube and add $50 \mu \mathrm{L}$ of elution buffer, incubated at room temperature for 2 minutes and when store purified DNA at $-20^{\circ} \mathrm{C}$.

\section{ITS-sequencing analysis}

A representative fungal isolate was selected for sequencing analysis. A part of the rDNA region ITS1-5.8S rDNA-ITS4 was amplified using the forward (ITS1) primer pairs. The sequencing of the product PCR was carried out in an automatic sequencer ABI PRISM 3730XL analyzer using Big Dye TM Terminator Cycle Sequencing Kits following the protocols supplied by the manufacturer. Single-pass sequencing was performed on each template using ITS1 primer. The fluorescent-labeled fragments were purified from the unincorporated terminators with an ethanol precipitation protocol. The samples were resuspended in distilled water and subjected to electrophoresis in an ABI 3730xl sequencer (Macrogen).

\section{Computational analysis (BLASTn) ITS}

The sequences were analyzed using BLAST program (http://www.ncbi.nlm.nih. Gov/ BLAST) Sequences were aligned using Align Sequences Nucleotide BLAST.

\section{Comparison between isolates using RAPD-PCR Reactions}

A set of 14 primers RAPD (Table, 1) was used to detection the polymorphism among the 5 fungal isolates of Alternaria (AM1, AM2, AM5, AM6 and AM11) and the 5 fungal isolates of Bipolaris (BM3, BM8, BM19, BM20 and BM22). The amplification reaction was carried out in 25 $\mu \mathrm{L}$ reaction volume containing $1 \mathrm{X}$ PCR buffer, 1.5 mM MgCl2, $0.2 \mathrm{~m}$ MdNTPs, $1 \mu \mathrm{M}$ primer, $1 \mathrm{U}$ Taq DNA polymerase and $30 \mathrm{ng}$ template DNA. 


\section{Thermocycling Profile and Detection of the PCR Products}

PCR amplification was performed in a Perkin - Elmer/ Gene Amp® PCR System 9700 (PE Applied Biosystems) programmed to fulfill 35 cycles after an initial denaturation cycle for $5 \mathrm{~min}$ at $94^{\circ} \mathrm{C}$. Each cycle consisted of a denaturation step at $94^{\circ} \mathrm{C}$ for $1 \mathrm{~min}$, an annealing step at $36^{\circ} \mathrm{C}$ for $1 \mathrm{~min}$, and an elongation step at $72^{\circ} \mathrm{C}$ for 1.5 min. The primer extension segment was extended to $7 \mathrm{~min}$ at $72^{\circ} \mathrm{C}$ in the final cycle. The amplification products were resolved by electrophoresis in a $1.5 \%$ agarose gel containing ethidium bromide $(0.5 \mu \mathrm{g} / \mathrm{mL})$ in 1 X TBE buffer at 95 volts. A $100 \mathrm{bp}$ DNA ladder was used as a molecular size standard. PCR products were visualized on UV light and photographed using a Gel Documentation System (BIO-RAD 2000).

Table 1. Sequence of the fourteen arbitrary primers RAPD - PCR.

\begin{tabular}{llll}
\hline Primer & Sequence 5' to 3' & Primer & Sequence 5' to 3' \\
\hline OPA05 & AGGGGTCTTG & OPB07 & GGTGACGCAG \\
OPA06 & GGTCCCTGAC & OPB12 & CCTTGACGCA \\
OPA08 & GTGACGTAGG & OPB13 & TTCCCCCGCT \\
OPA13 & CAGCACCCAC & OPB17 & AGGGAACGAG \\
OPA20 & GTTGCGATCC & OPC01 & TTCGAGCCAG \\
OPB02 & TGATCCCTGG & OPC05 & GATGACCGCC \\
OPB06 & TGCTCTGCCC & OPC13 & AAGCCTCGTC \\
\hline
\end{tabular}

\section{Data analysis}

The banding patterns generated by RAPD PCR marker analyses were compared to determine the genetic relatedness of the samples under study. Clear and distinct amplification products were scored as ' 1 ' for presence and ' 0 ' for absence of bands. Bands of the same mobility were scored as identical. The genetic similarity coefficient (GS) between two genotypes was estimated according to Dice coefficient (Sneath and Sokal, 1973).

Dice formula: GSij $=2 a /(2 a+b+c)$

Where GSij is the measure of genetic similarity between individuals $i$ and $j, a$ is the number of bands shared by $i$ and $j, b$ is the number of bands present in $i$ and absent in $j$, and $c$ is the number of bands present in $j$ and absent in $i$. The similarity matrix was used in the cluster analysis. The cluster analysis was employed to organize the observed data into meaningful structures to develop taxonomies. At the first step, when each accession represents its own cluster, the distances between these accessions are defined by the chosen distance measure (Dice coefficient). However, once several accessions have been linked together, the distance between two clusters is calculated as the average distance between all pairs of accessions in the two different clusters. This method is called Unweighted Pair Group Method using Arithmetic Average (UPGMA) (Sneath and Sokal, 1973).

\section{Host rang}

Pathogenic capability of Bipolaris sorokiniana and Alternaria sesami isolates were tested on 11 plant species belonged to three families. The tested plants were: Sorghum, Maize, Wheat, Barley, Rice, Tomato, Broad bean, Datora, Potato, Pepper and Bean. The tested plants were sprayed to runoff with $100 \mathrm{~mL}$ of 106 conidia $/ \mathrm{mL}$ of conidial suspension of appropriate isolate and loosely enclosed in a plastic bag for $24 \mathrm{~h}$. The inoculated plants were kept under open field conditions. Ten plants from each plant species were used for each isolate. The reactions of the inoculated plants were monitored daily for 4 weeks after inoculation date.

\section{Isolates aggressiveness}

Aggressiveness of five identified isolates was evaluated on leaves of sesame plants (variety Shandawil-3) after artificial inoculation using spraying method. Inoculum of each fungal isolates were prepared as mentioned above. The tested plants were sprayed to runoff with $100 \mathrm{~mL}$ of fungal suspension of appropriate isolate and loosely enclosed in a plastic bag for $24 \mathrm{~h}$. The inoculated plants were kept in a greenhouse in which the average of temperature was $28^{\circ} \mathrm{C}$. Ten plants were used for each isolate and the assays were repeated three times and the results of all tests were averaged and reported. The reactions were evaluated 20 days after inoculation according to the following indices:

*Disease index (0-4) For Alternaria severity assessment.

$0=$ No symptoms.

$1=$ Tiny spots with number $<20$ spots $/$ leaf.

$2=$ Small sized spots $(<0.2 \mathrm{~mm})$ with number $>20$ and $<60$ spots /leaf.

$3=$ Medium sized spots $(>2 \mathrm{~mm})$ spots with total spot number $>60$ and $<120$ spot / leaf.

$4=$ As in three, but spots number $>120$ spot $/$ leaf, leaves defoliation and plant collapse.

*Disease index (0-4) For Bipolaris severity assessment.

$0=$ No symptoms.

$1=$ Small sized spots $(<0.5 \mathrm{~mm})$ with number $<$ 20 spots / leaf.

$2=$ Medium sized spots $(>5 \mathrm{~mm})$ with number $>20$ and $<60$ spots /leaf. 
$3=$ Extended blotches $(>5 \mathrm{~mm})$ with total number $>60 /$ leaf.

$4=$ As in three with severe defoliation and plant collapse.

\section{Cultivar reaction}

The pathological response of three sesame cultivars (viz., Shandawil-3, Suhaj-1 and Giza-32) to infection by Alternaria sesami and Bipolaris sorokiniana were tested in pots experiment. The conidial suspension was prepared as described in pathogenicity test. The number of conidia were counted using the hemocytometer and adjusted to $2 \times 10^{3}$ conidia/mL (Ojiambo, et al., 1998). Forty days old plants of each variety were inoculated and kept as described earlier (in pathogenicity test). Twenty days after inoculation the disease severity was recorded as previously.

\section{Statistical analysis}

It's worth to be noted, the experiments of varietal reaction and isolates aggressiveness was designed as complete blotted design with five replicates for each variety. Data were subjected to ANOVA by using (Anonymous, 1988) and significant difference among the treatments was portioned by LSD test multiple range test at probability levels of $p=0.05$.

\section{RESULTS}

\section{Pathogens isolation}

Isolation from symptomatic material of sesame plant on PDA medium yielded many fungal colonies growth with various cultural characteristics. After purification processes, the fungal isolates suspected to be causal agent of leaf spot were selected and non-regarded isolates were discarded. Generally, 19 fungal isolates were selected. The selected isolates were kept at $5{ }^{\circ} \mathrm{C}$ on PDA slant to accomplish the study.

\section{Identification of the fungal pathogens \\ Cultural and microscopic characteristics:}

Based on the characters of colony and morphological characters of conidiophores and conidia, the selected fungal isolates were restricted in the fungal genera of Alternaria and Bipolaris. The measurements of conidiophores and conidia were also found comparable with the standard measurements of Alternaria sesami and Bipolaris sorokiniana given in literatures.

On PDA medium, the Alternaria isolates colonies were fast growing, appeared initially as white with granular texture and then turning to greenish grey colour (Fig. 1). Aged culture appeared completely black with no aerial mycelium. In microscopically observation, the conidiophores of the fungal isolates were simple bearing acropetal chains (blastocatenate) of multicellular conidia at the apex. Conidia were pale brown colored, obclavate, with a hyaline beak (Fig. 2). The number of horizontal and vertical septa varied from four to12 and zero to six respectively.

In the same medium, the Bipolaris isolates varies in morphology, from dark olive-brown to grayish suppressed mycelial growth (Fig. 1). In microscopically observation, simple conidiophores are produced in fresh culture, and may be single or clustered. Conidiophores measure 6-10 x 110-220 $\mu \mathrm{m}$ with 6-11 septa. The conidia (Fig. 2), are olive-brown and elliptical with 5 to 9 cells and measure $15-28 \times 40-120 \mu \mathrm{m}$. They arise from pores beneath each conidiophore septum and exhibit bipolar germination, or development of hyphae from each end of the spore (Fig. 3).

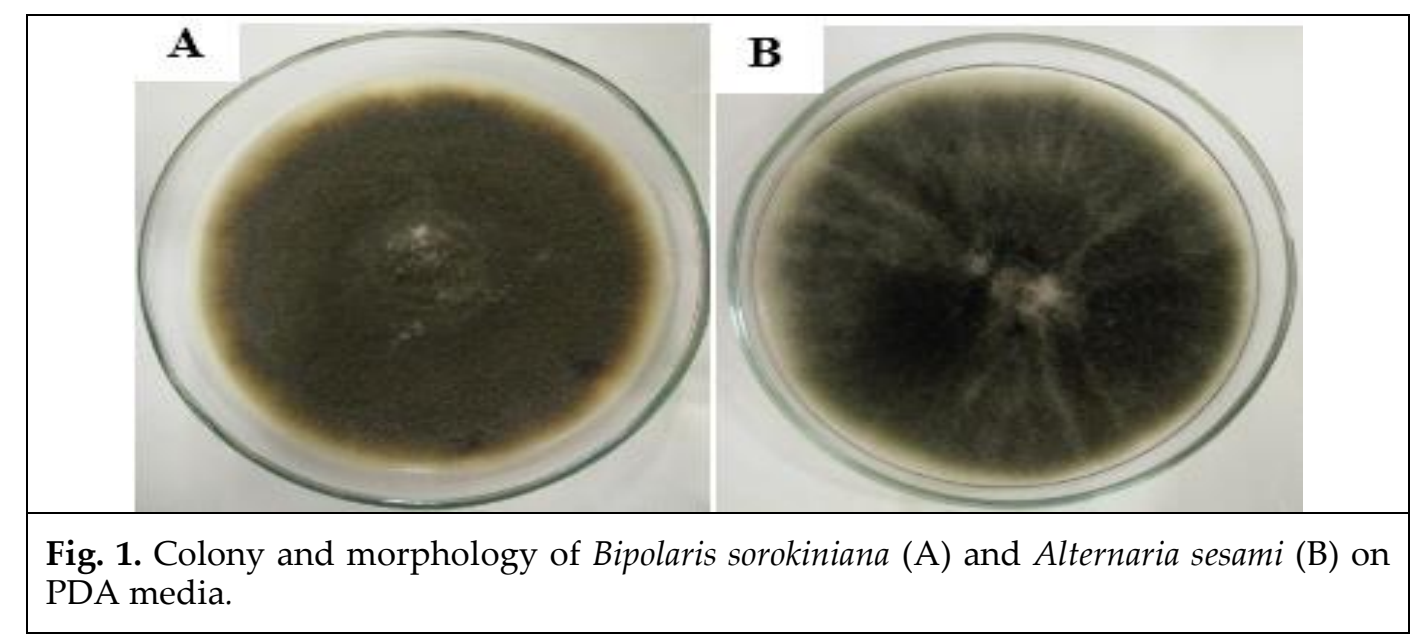




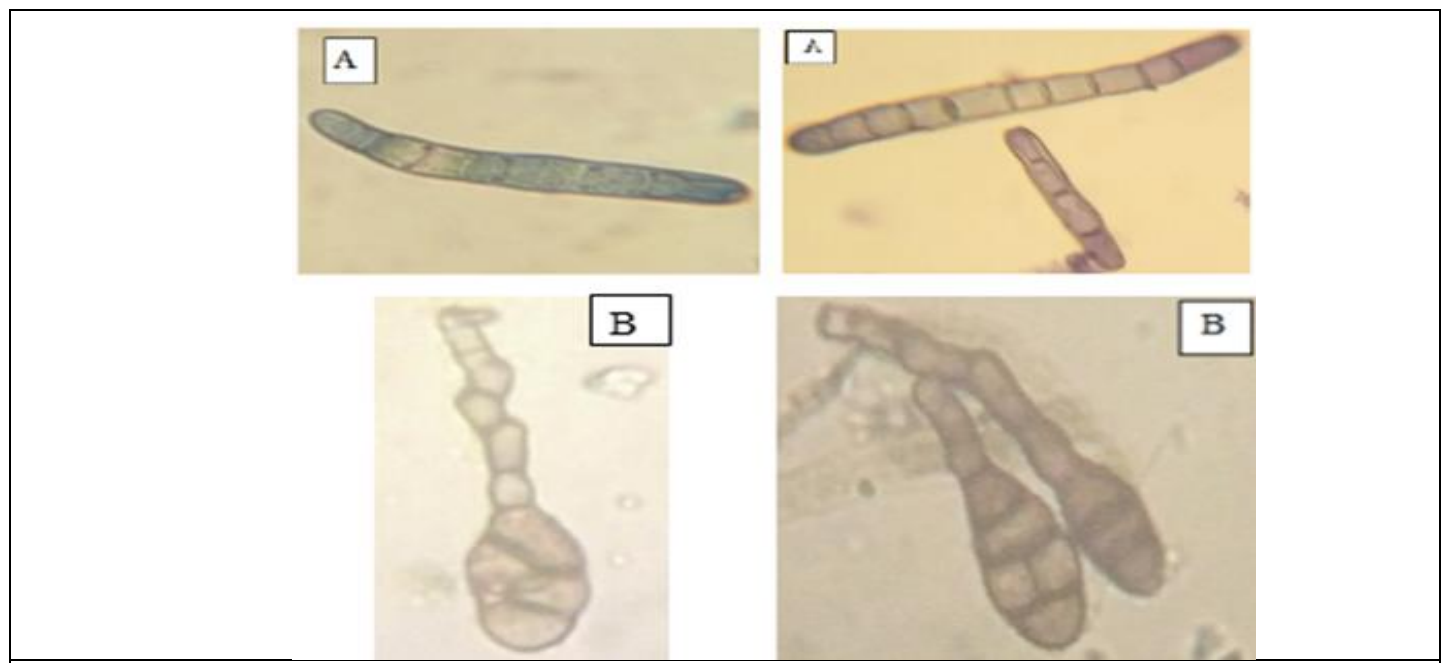

Fig 2. Microscopically characteristics of conidio spore of Bipolaris sorokiniana (A) and Alternaria sesami (B).

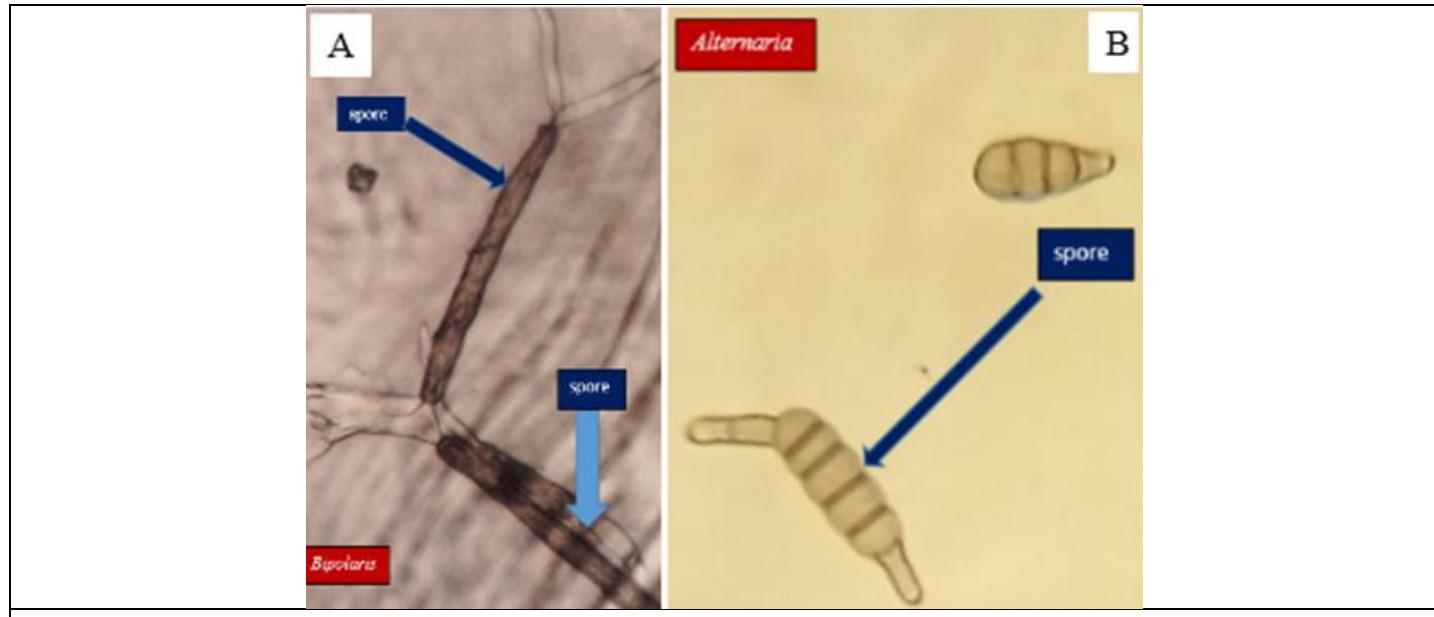

Fig. 3. Type of spore germination in B. sorokiniana (A) and A. Sesami (B).

\section{Pathogenicity test}

All tested isolates of Alternaria sesame and Bipolaris sorokiniana evoke typical symptoms of leaf spot disease on inoculated sesame plants in eight to ten days from inoculation. The sesame plants inoculated with the Bipolaris isolates initially, showed small brown to purple lesions which expanded with time to distinct lesions or patches with reddish brown color that girdle the leaf blade giving the plant turf an overall purple cast (Fig. 4). leaves eventually withered with dry tan to a light color.
The sesame plants inoculated with the Alternaria isolates showed small circular white coloured spots on the lower leaves, which later became brown and irregular in shape with concentric rings or zones (Fig. 4) and spread to upper leaves. As the disease advanced, the spots enlarged with the central portion turning olivaceous brown. In advanced stages the spots developed brown margin with concentric rings. Eventually the spots coalesced resulting in withering, extensive drying and shedding of the leaves. 

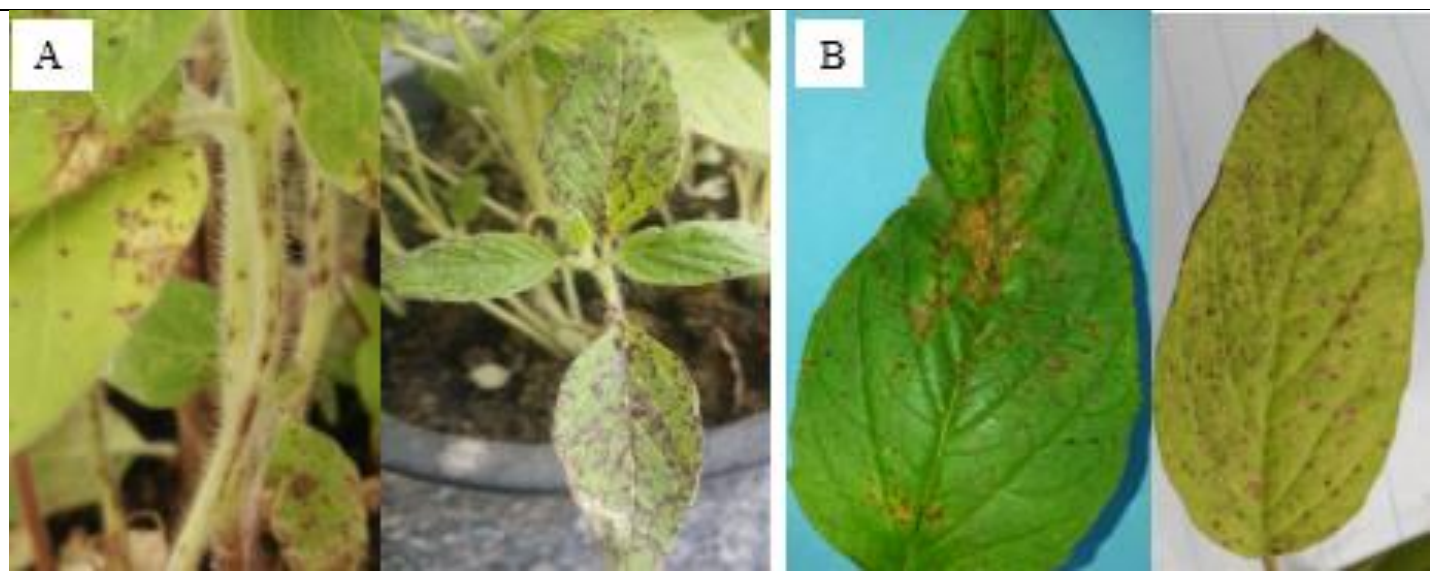

Fig. 4. Symptoms on sesame leaves resulted from artificially inoculation by B. sorokiniana (A) and A. sesami (B).

\section{Molecular identification (ITS rDNA gene)}

PCR using primer pairs ITS1/ITS4 yielded specific species band of amplification product for both fungal isolates (Fig. 5). ITS pattern of Fungal isolates was subjected for ITS sequence analysis.
BLAST analysis of the nucleotide sequence of the ITS region of Alternaria isolate showed 99\% similarity with Alternaria sesami strains. whereas BLAST analysis of the nucleotide sequence of the ITS region of Bipolaris isolate showed 93\% similarity with Bipolaris sorokiniana.

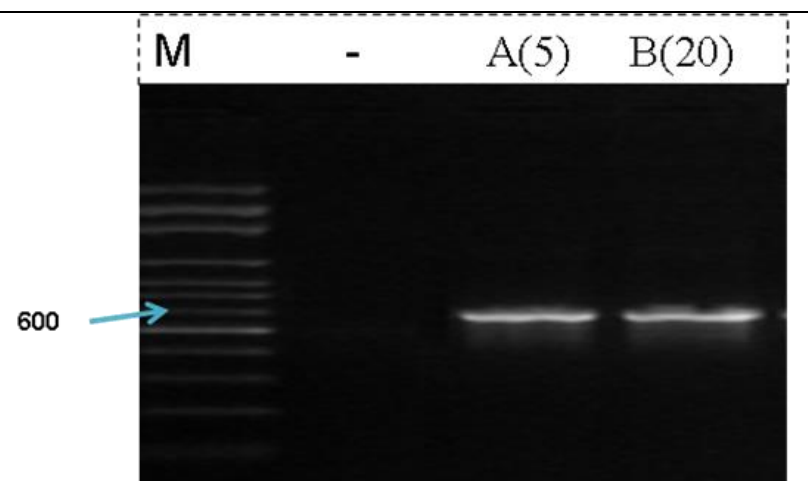

Fig. 5. PCR products from amplification of ITS primer (ITS1F-ITS4R) region of rDNA of isolates. M: 100bp plus DNA Marker, -: negative sample, A (A. sesami) and B (B. sorokiniana).

\section{Randomly Amplified Polymorphic DNA (RAPD)}

\section{Polymorphism detected by RAPD markers}

Fourteen RAPD primers were screened with the DNA of the fungal isolates to detect the Polymorphism among these isolates. Five isolates of Alternaria (AM1, AM2, AM3, AM4 and AM5) and five isolates of Bipolaris (BM1, BM2, BM3, BM4 and BM5) were screened separately. These produced multiple band profiles with a number of amplified DNA fragments.

In the case of Bipolaris isolates, multiple band profiles with a number of amplified DNA fragments ranging from 8 to 19 were produced (Table, 2 and Fig. 6). The total number of fragments produced by the 14 primers was 168 with an average of 12 fragments/primer. While, the number of polymorphic fragments ranged from 2 to 14 . A maximum number of 19 amplicons were amplified with primer OPA-20, while the minimum number of fragments (8) was amplified with primers OPB-17. The highest number of polymorphic bands (14) was obtained with primers OPA-06, which exhibited the highest percentage (100\%) of polymorphism. also revealed that the total number of polymorphic amplicons obtained by the fourteen studied primers was 100 . This corresponds to a level of polymorphism of $57 \%$ and an average number of polymorphic fragments/primers of 7.1.

In the case of Alternaria isolates, multiple band profiles with a number of amplified DNA fragments ranging from 8 to 16 were produced (Table, 3 and Fig. 7). The total number of 
fragments produced by the 14 primers was 147 with an average of 10.5 fragments/primer. While, the number of polymorphic fragments ranged from 1 to 9 . A maximum number of 16 amplicons were amplified with primer OPA-20, while the minimum number of fragments (8) was amplified with primers (OPA-05, OPA-08, PB-12 and OPB-17). The highest number of polymorphic bands (9) was obtained with primers OPA-20, which exhibited the highest percentage $(56 \%)$ of polymorphism. Also revealed that the total number of polymorphic amplicons obtained by the 14 studied primers was 52. This corresponds to a level of polymorphism of $36 \%$ and an average number of polymorphic fragments/primers of 3.7.

Table 2. Primer name, Primer sequence, Total bands (TB), monomorphic bands (MB), polymorphic bands $(\mathrm{PB})$, percentage of polymorphism $(\% \mathrm{P})$, Frequency $(\mathrm{F})$ and size detected by RAPD.

\begin{tabular}{|c|c|c|c|c|c|c|c|}
\hline Primer & Sequence 5' to 3' & TB & $\mathrm{MB}$ & PB & $\% \mathrm{P}$ & $\mathrm{F}$ & Size \\
\hline OPA05 & AGGGGTCTTG & 14 & 2 & 12 & 86 & 0.5 & $270: 1470$ \\
\hline OPA06 & GGTCCCTGAC & 15 & 1 & 14 & 93 & 0.4 & $200: 1540$ \\
\hline OPA08 & GTGACGTAGG & 9 & 0 & 9 & 100 & 0.3 & $140: 640$ \\
\hline OPA13 & CAGCACCCAC & 11 & 8 & 3 & 27 & 0.9 & $340: 1620$ \\
\hline OPA20 & GTTGCGATCC & 19 & 7 & 12 & 63 & 0.7 & $190: 1500$ \\
\hline OPB02 & TGATCCCTGG & 11 & 6 & 5 & 45 & 0.7 & $280: 1500$ \\
\hline OPB06 & TGCTCTGCCC & 9 & 4 & 5 & 56 & 0.7 & $280: 1500$ \\
\hline OPB07 & GGTGACGCAG & 12 & 5 & 7 & 58 & 0.7 & 230:1100 \\
\hline OPB12 & CCTTGACGCA & 9 & 7 & 2 & 22 & 0.9 & $390: 1190$ \\
\hline OPB13 & TTCCCCCGCT & 9 & 6 & 3 & 33 & 0.9 & 320:990 \\
\hline OPB17 & AGGGAACGAG & 8 & 6 & 2 & 25 & 0.9 & $350: 1490$ \\
\hline OPC01 & TTCGAGCCAG & 16 & 11 & 5 & 31 & 0.9 & $140: 1130$ \\
\hline OPC05 & GATGACCGCC & 11 & 2 & 9 & 82 & 0.5 & 220:1190 \\
\hline OPC13 & AAGCCTCGTC & 15 & 3 & 12 & 80 & 0.5 & $260: 1440$ \\
\hline Total & & 168 & 68 & 100 & & & \\
\hline Mean & & 12 & 4.9 & 7.1 & 57 & 0.7 & \\
\hline
\end{tabular}

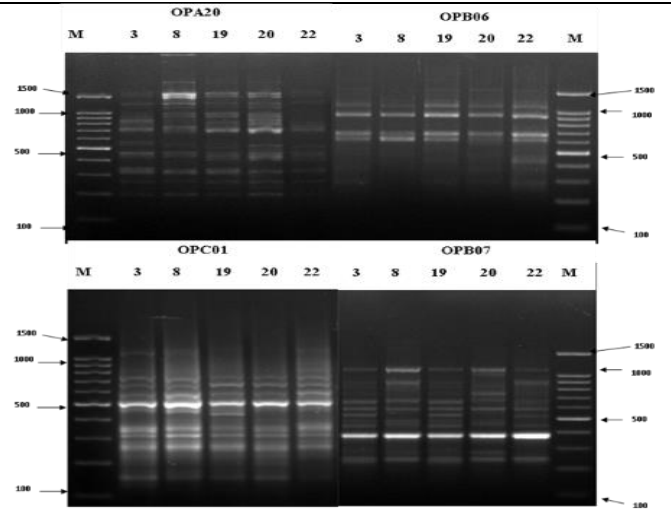

Fig 6. RAPD profiles for the five fungal isolates of (Bipolaris sorokiniana) as detected with primers OPA-20, OPB-06, OPC-01 and OPB-07. Strain BM3, BM8, BM19, BM20 and BM22, M: 100bp ladder DNA marker.

Table 3. Primer name, Primer sequence, Total bands (TB), monomorphic bands (MB), polymorphic bands $(\mathrm{PB})$, percentage of polymorphism (\%P), Frequency $(\mathrm{F})$ and size detected by RAPD Alternaria sesami.

\begin{tabular}{|c|c|c|c|c|c|c|c|}
\hline Primer & Sequence 5 ' to $3^{\prime}$ & $\mathrm{TB}$ & $\mathrm{MB}$ & PB & $\% \mathrm{P}$ & $\mathrm{F}$ & Size \\
\hline OPA05 & AGGGGTCTTG & 8 & 5 & 3 & 38 & 0.8 & $130: 730$ \\
\hline OPA06 & GGTCCCTGAC & 13 & 9 & 4 & 31 & 0.8 & $190: 1200$ \\
\hline OPA08 & GTGACGTAGG & 8 & 7 & 1 & 13 & 0.9 & $210: 1170$ \\
\hline OPA13 & CAGCACCCAC & 9 & 5 & 4 & 44 & 0.8 & $300: 970$ \\
\hline OPA20 & GTTGCGATCC & 16 & 7 & 9 & 56 & 0.8 & $200: 1900$ \\
\hline OPB02 & TGATCCCTGG & 10 & 9 & 1 & 10 & 1.0 & $320: 1600$ \\
\hline OPB06 & TGCTCTGCCC & 9 & 5 & 4 & 44 & 0.8 & $320: 1540$ \\
\hline OPB07 & GGTGACGCAG & 11 & 8 & 3 & 27 & 0.9 & $270: 1370$ \\
\hline OPB12 & CCTTGACGCA & 8 & 6 & 2 & 25 & 0.9 & $250: 2100$ \\
\hline OPB13 & TTCCCCCGCT & 13 & 8 & 5 & 38 & 0.8 & $280: 1500$ \\
\hline OPB17 & AGGGAACGAG & 8 & 6 & 2 & 25 & 0.9 & $250: 1660$ \\
\hline OPC01 & TTCGAGCCAG & 13 & 8 & 5 & 38 & 0.9 & $360: 1890$ \\
\hline OPC05 & GATGACCGCC & 12 & 7 & 5 & 42 & 0.8 & $230: 1550$ \\
\hline OPC13 & AAGCCTCGTC & 9 & 5 & 4 & 44 & 0.8 & $260: 1070$ \\
\hline Total & & 147 & 95 & 52 & & & \\
\hline Mean & & 10.5 & 6.8 & 3.7 & 35 & 0.9 & \\
\hline
\end{tabular}




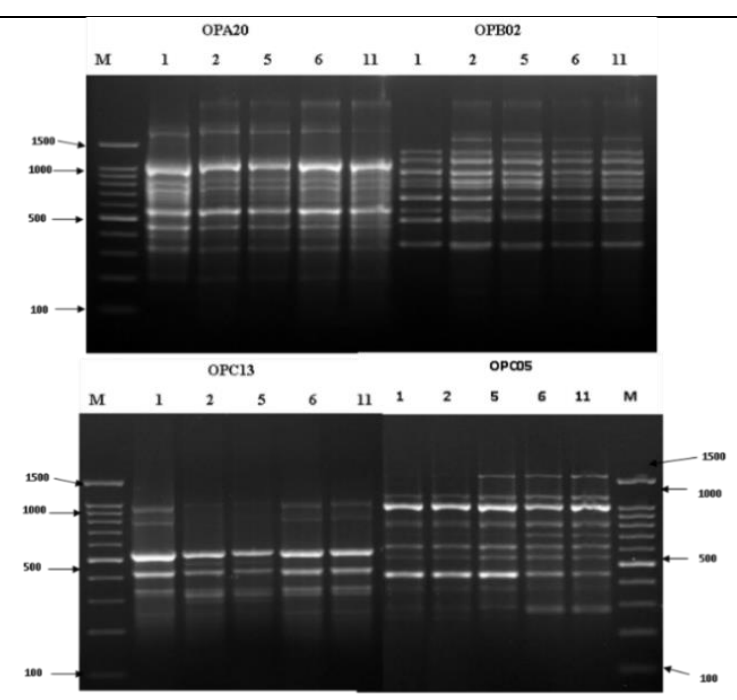

Fig. 7. RAPD profiles for the five fungal isolates of (Alternaria sesami) as detected with primers OPA-20, OPB-02, OPC-05 and OPC-13. Strain(AM1, AM2, AM5, AM6 and AM11), M: 100bp ladder DNA marker.

\section{Genetic relationships among the five fungal isolates as revealed by RAPD Markers}

To examine the genetic relationships among each group of fungal isolates based on RAPD results, the scored data were analyzed using the dice coefficient to compute the similarity matrices. These similarity matrices were used to generate a dendrogram using the UPGMA method. In the case of Bipolaris isolates, the estimated genetic similarities ranged from $74 \%$ to $82 \%$ revealing very high levels of genetic similarity among the studied accessions. The highest genetic similarity percentage $(82 \%)$ accrued between isolate 8 and isolate 20, while the lowest genetic similarity $(74 \%)$ was detected between isolate 3 and isolate 8 . In the case of Alternaria isolates, the estimated genetic similarities ranged from $85 \%$ to $96 \%$. This also revealing very high levels of genetic similarity among the studied accessions. The highest genetic similarity (96\%) accrued isolate 2 and isolate 5 , while the lowest genetic similarity
(85\%) was detected between isolate 1 and isolate 5 and between isolate 1 and isolate 6 .

\section{Host range}

Pathogenic capability of Bipolaris sorokiniana and Alternaria sesami isolates were tested on 11 plant species belonged to three families (Table, 4). In general, the isolates varied in its pathogenicity on the tested plants. The results showed that, all isolates of Bipolaris sorokiniana were pathogenic on tomato, maize, broad bean, bean, sorghum and wheat. Also, none of these isolates produced any symptoms on the tested plants. On the other hand, the isolates of Alternaria sesami markedly varied in its pathogenicity on the tested plants. Prove this, isolates AM1 and AM11 produced symptoms on one plant (tomato in the case of AM1 and bean in the case of AM11); isolate AM2 produced symptoms on two plants (broad bean and sorghum); isolates AM5 and AM6 produced symptoms on four plants (tomato, broad bean, bean and sorghum).

Table 4. Host range of B. sorokiniana and Alternaria sesami on different plants species.

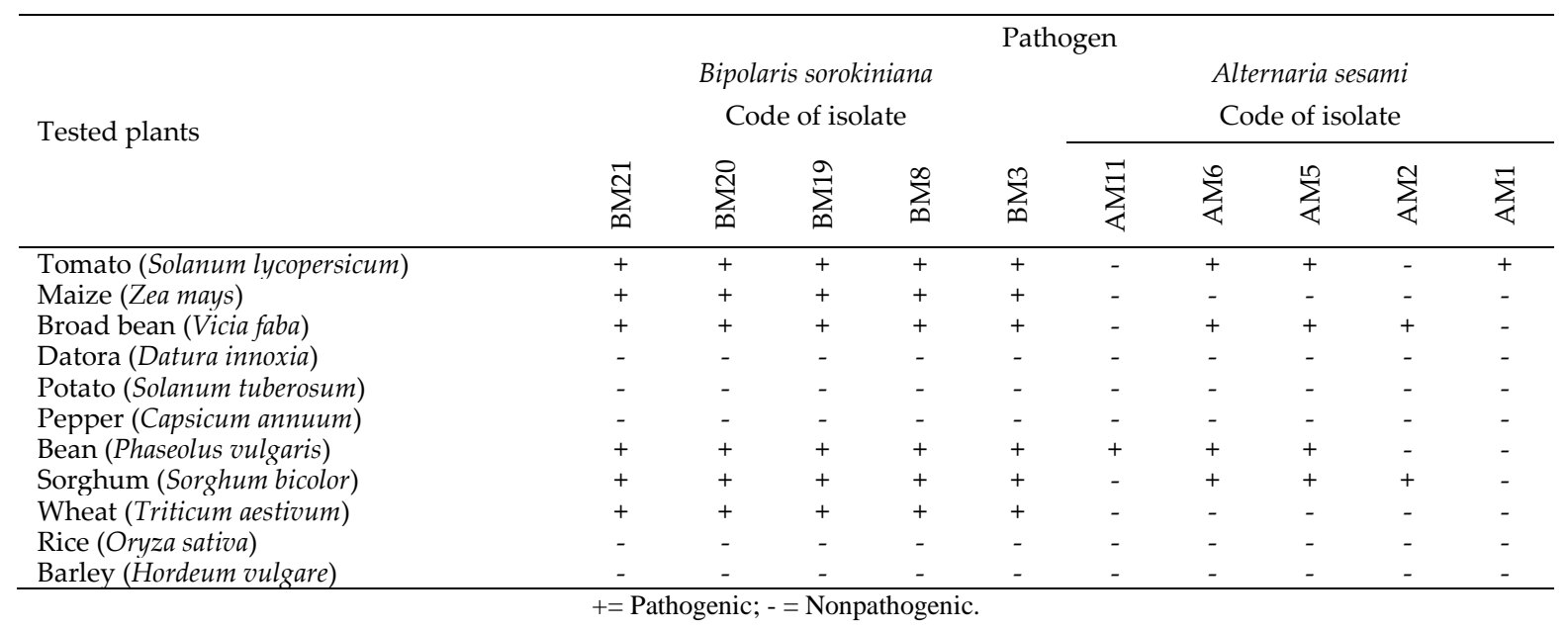




\section{Isolates aggressiveness}

Differences in aggressiveness between the isolates of each fungus were evaluated by artificial inoculation of sesame plants using spray inoculation methods. Generally, all isolates generate typical leaf spot symptoms on inoculated plants within eight to 12 days. Nevertheless, some differences in symptoms expression and its progress were detected in the duration of the test.

In the case of Bipolaris isolates, disease severity significantly differed $(P \leq 0.05)$ among the isolates. The values of aggressiveness of the isolates ranged from 2.2 to 3.2 of disease severity. Isolates designated BM20 were the highest in aggressiveness level (Table, 5). In the case of Alternaria isolates, the values of aggressiveness of the isolates ranged from 2.3 to 3.1 of disease severity. Isolates designated AM5 were the highest in aggressiveness level (Table, 5).

Table 5. Isolate aggressiveness of $B$. sorokiniana and $A$. sesami on sesame cv. Shandawil-3.

\begin{tabular}{lcc}
\hline Pathogen & Code of isolates & Disease severity \\
\hline \multirow{4}{*}{ B. sorokiniana } & BM21 & 2.4 \\
& BM20 & 3.2 \\
& BM19 & 2.2 \\
& BM8 & 2.8 \\
& BM3 & 2.4 \\
A. sesami & AM11 & 2.4 \\
& AM6 & 2.5 \\
& AM5 & 3.1 \\
& AM2 & 2.5 \\
& AM1 & 2.3 \\
\cline { 2 - 3 }
\end{tabular}

\section{Cultivar reaction}

The disease reaction of three cultivars of sesame to Bipolaris sorokiniana and Alternaria sesami were assessed by artificially inoculation of sesame plants with conidial suspension of the tested fungi. Generally, all varieties showed positive response to infection bay both fungi but the severity degree varied significantly among the tested varieties (Table, 6). Variety Shandawil-3 showed the highest degree of susceptibility to $B$. sorokiniana (3.8) followed by Giza-32 (3.4) and Suhag-1 (3.2). On the other hand, variety Shandawil-3 showed the highest degree of susceptibility (3.2) followed by Giza-32 (3.0) and Suhag-1 (2.8) to A. sesami.
Table 6. Reaction of three sesame cultivars against $B$. sorokiniana and $A$. sesami.

\begin{tabular}{lcc}
\hline \multicolumn{2}{c}{ Disease severity } \\
Cultivars & Bipolaris sorokiniana & Alternaria sesami \\
\hline Shandawil-3 & 3.8 & 3.2 \\
Suhaj-1 & 3.2 & 2.8 \\
Giza-32 & 3.4 & 3.0 \\
LSD & 0.4 & 0.5 \\
\hline
\end{tabular}

\section{DISCUSSION}

In the present study, sesame plants showing leaf spot symptoms were sampled from three Egyptian governorates (Al -Buhayrah, AlFayuwm and Beni Suef) during the summer of 2016 growing season. Isolation process from these collected samples resulted in obtain many fungal isolates suspected to be pathogenic to sesame. Depending on the identification schema, only ten isolates belongs to the fungal genera, Alternaria and Bipolaris were found to be pathogenic. Later, these isolates were identified depending on DNA sequencing to their species level as Bipolaris sorokiniana (five isolates) and Alternaria sesami (five isolates). Bipolaris sorokiniana (Sacc.) Shoemaker (Sivanesan, 1990) (teleomorph Cochliobolus sativus) is known as causal agent of common root rot, leaf spot, seedling blight, head blight of several host plants like wheat and barley for instance. Several synonyms of the anamorph have been used like Hilmenthosporium sorokiniana, Drechslera sorokiniana and Hilmenthosporium sativum (Maraite et al., 1998).

Previously its generic name Bipolaris was proposed by Shoemaker (1959) having the fusoid, straight or curved conidia with bipolar germination and characterized by thick-walled, elliptical conidia (60-120um x 12-20 um) with 4-8 septa. The colony of the fungus has interwoven hyphae as a loose cottony mass white or light to grey color depending on the isolates. The fungus is differentiated from other members of the genus Bipolaris on the basis of morphological characters of conidiospores and conidiophores (Kumar et al., 2002). Pathogenicity tests were conducted to establishing the potential of the various fungal isolates that isolated from symptomatic sesame plants to cause leaf spot symptoms. Under artificial inoculation conditions only ten isolates produced visible symptoms that were observed seven-ten days after inoculation. The re-isolation from infected plant parts yielded similar fungus, hence proved pathogenicity of Alternaria sesami and Bipolaris sorokiniana. Similarly, pathogenicity test of Alternaria sesami was confirmed by (Mc Donald, 1964; Yu, et al., 1982). The disease 
symptoms were mainly manifested on the leaf blade as brown, round to irregular spots varying from one $\mathrm{mm}$ to two $\mathrm{cm}$ in diameter. Initially water soaked appeared which later turned greyish to dark brown with concentric zonation. In severe infections several spots coalesced and defoliation occurs. The dark brown water-soaked lesions were also seen on the stem, midrib. Similar symptoms of $A$. sesami have been reported by many workers (Malaguti et al., 1972; Davide, 1975; Sahani and Mahapatra, 2014). The ITS universal barcode marker was used to identify Bipolaris species and Alternaria species. BLAST analysis of the nucleotide sequence of the ITS region of both pathogens showed 93\% similarity with Bipolaris sorokiniana strains in the case of Bipolaris Isolate and 99\% similarity with Alternaria sesami strains in the case of Alternaria isolate. ITS locus is the universal barcode marker for fungi (Schoch, et al., 2012). Most recently, taxonomists have accepted that a secondary locus is essential for the accurate identification of many taxa (Madrid et al., 2014; Manamgoda et al., 2012 and 2015; Tan et al., 2014; Stielow et al., 2015).

DNA markers have become a powerful tool to study taxonomy and molecular genetic of a variety of organisms. The random amplified polymorphic DNA (RAPD) allows quick assessment of genetic variability in various taxa, and has been used to study inter and intraspecific variability among isolates of several fungal species used in biological control (Inglis et al., 2001; Tigano-Milani et al., 1995a and b). The RAPD-PCR technique was used to differentiate the diverse between five different isolates of $B$. sorokiniana and five different isolates of $A$. sesami. The results showed that there a percentage of $68 \%$ similarity between the five isolates of $A$. sesami and $49 \%$ of $B$. sorokiniana. Hereby, these results confirm that the isolates of $A$. sesami and $B$. sorokiniana are genetically differed and that differences in the pathogenicity and morphology is due to the genetic diversity. The RAPD is commonly used for genetic differentiation analysis because it's simple, sensitive and rapid for the detection, differentiation and determination of phylogenetic relationship between isolates of a morphological species of several pathogens. The combination of RAPD and PCR procedures has the potential to detect polymorphism throughout the entire genome as compared with other nucleic acid-based techniques (Peever and Milgroom 1994; Peltonen et al., 1996; Jonsson et al., 2000; Wu, et al., 2003; Rau et al., 2003; Leisova et al., 2005; Serenius, 2006; Peltonen et al., 1996).

Pathogenic capability of Bipolaris sorokiniana and Alternaria sesame isolates were tested on 11 plant species belonged to three families. The isolates of Bipolaris relatively showed unspecific pathogenic response toward the tested plants since they were pathogenic to number of the tested plants more than that in the case of the Alternaria isolates. Also, they were uniformed in this response since, all isolates produced symptoms on Tomato, Maize, Broad bean, Bean, Sorghum and Wheat while, all isolates failed to induce any symptoms on Datora, Potato, Rice and Barley. This pathogen infects number of both cultivated and wild plants. Eighteen monocotyledonous plants have been identified as its hosts (Balogh, et al., 1991). More than 29 species of Gramineae and other crops in Northeastern China,65 species of Gramineae in Yellow and Hai river region and 17 plant species in Guangdong province are reported as the hosts of this pathogen (Chang and $\mathrm{Wu}, 1997)$. On the contrary, the isolates of Alternaria sesami markedly varied in its pathogenicity on the tested plants. Prove this, isolates Am1and AM11 produced symptoms on one plant (Tomato in the case of AM1 and Bean in the case of AM11); isolate AM2 produced symptoms on two plants (Broad bean and Sorghum); isolates AM5 and AM6 produced symptoms on four plants (Tomato, Broad bean, Bean and Sorghum). The presence of other hosts plays an important role in disease epidemic. The primary inoculum of $B$. sorokiniana and Alternaria sesami comes from several sources such as weed hosts, soil, crop debris which enhances the disease level. The weeds as a collateral host of $B$. sorokiniana and Alternaria spp. is considered as a possible reason for perceived increase in leaf spot diseases and cause major losses to many crops (Hobbs and Morris, 1996). The perennial nature of some weeds and their presence in sesame growing areas is potential to facilitate over wintering and survival of the pathogen. Different aggressiveness behavior of the both pathogen to the sesame host was observed during aggressiveness analysis. Generally, all isolates generate typical leaf spot symptoms on inoculated plants within seven to 12 days. Nevertheless, some differences in symptoms expression and its progress were detected in the duration of the test. In both cases of isolates type one isolate significantly differed $(P \leq 0.05)$ in its aggressiveness level from other isolates. The assessment of the aggressiveness of the pathogen is the frontier at which host and pathogen interact. It is an obvious benefit in developing a better understanding of the host pathogen relationship (Jain and Prabhu 1976). The extent of variability in the aggressiveness of $B$. sorokiniana has been investigated worldwide on other hosts but sesame was not included. The aggressive type of B. sorokiniana remains potentially viable in the shriveled seeds (Rashid, 2005). Mikhailova et al. (2002) who studied the aggressiveness 
behavior of 11 isolates of $B$. sorokiniana collected from different geographical location in Russia and checked on ten varieties of wheat and found significant difference in fungal strains behavior. Whereas Duveiller and Garcia (2000) isolated 27 isolates of B. sorokiniana (from roots, leaves and grains of spring wheat) collected from a single site in Mexico and found no clear difference between groups of isolates. They reported that, this behavior of the fungus appeared as a continuum of isolates differing in aggressiveness. Controlling plant disease with the use of cultural practices and resistant varieties are considered as safest control measures. The disease reaction of three cultivars of sesame to Bipolaris sorokiniana and Alternaria sesami revealed that none of the three sesame cultivars were completely resistant against the both pathogens. Generally, all cultivars showed positive response to infection by both fungi with no significant differences in severity degree among the tested cultivars. In the case of Bipolaris, cultivar Shandawil-3 showed the highest degree of susceptibility followed by Giza32 and Suhag-1. In the case of Alternaria, cultivar Shandawil-3 showed the highest degree of susceptibility followed by Giza-32and Suhag-1. Our results are in accordance to those of Ojiambo, et al., (1998), who found that, infection of Alternaria sesami varied from $8.96-24.80 \%$ in Kakamega and Siaya sesame varieties. Similarly, Jayaramaiah, et al., (1981) tested different sesame varieties against $A$. sesami under field and glass house conditions and observed that four sesame varieties namely JT-7, No.4, No.2 and E-8 were highly resistant.

\section{Conclusion}

From our results, the causal pathogen Bipolaris sorokiniana is considered the most prefiling pathogen among the sesame leaf spot causal pathogen in Egypt. This pathogen is responsible for serious losses of sesame crop.

\section{REFERENCES}

Agrios, G.N., 2005. Plant pathology, 5th edn. Academic Press. Amsterdam.

Alcorn, J.L., 1983. Generic concepts in Drechslera, Bipolaris and Exserohilum. Mycotaxon. 17, 1-86.

Alcorn, J.L., 1988. The taxonomy of Hilmenthosporium species. Ann. Rev. Phytopathol. 26, 37-56.

Anonymous, 1988). Microcomputer program analysis, Co. Hort. Software, Berkely, CA, USA.

Balogh, S., Ratai, R., Aponyi, I., Schweigert, A., Fuzi, I., 1991. A kalászosok helmintospóriumos levélszáradása (Hilmenthosporium leaf blight of small grains). KSZE Agrofórum, 2, 30-33.

Basavaraj, M.K., Ravindra, H., Girijesh, G.K., Karegowda, C., Shivayogeshwara, B., 2007. Evaluation of sesame genotypes for resistance to leaf blight caused by Alternaria sesami. Karnataka, J. Agric. Sci., 20 (4), 864864.

Berbee, M., Pirseyedi, M., Hubbard, S., 1999. Cochliobolus phylogenetics and the origin of known, highly virulent pathogens, inferred from ITS and glyceraldehyde-3-phosphate dehydrogenase gene sequences. Mycologia. 91, 964-977.

Bhale, M.S., Bhale, U., Khare, M.N., 1998. Diseases of important oilseed crops and their management. In: S.M.P., Khurana eds., Pathological Problems of Economic Crop Plants and their Management. Scientific Punlishers, India. pp. 251-279.

Cai, L., Giraud, T., Zhang, N., Begerow, D., Cai, G., Shivas, R.G., 2011. The evolution of species concepts and species recognition criteria in plant pathogenic fungi. Fungal Divers. 50, 121-133.

Cai, L., Hyde, K., Taylor, P., Weir, B., Waller, J., Abang, M., Zhang, J., Yang, Y., Phoulivong, S., Liu, Z., 2009. A polyphasic approach for studying Colletotrichum. Fungal Divers. 39, 183-204.

Chang, N., Wu, Y., 1997. Incidence and current management of spot blotch of wheat in China. In: Duveiller, E., Dubin, H.J., Reeves, J., McNab, A., eds., Hilmenthosporium Blight of Wheat: Spot Blotch and Tan Spot. D. F., CIMMYT, Mexico, pp. 119-133.

Davide, R.G., 1975. A review of diseases affecting upland crops in the Philippines. Regional Office for Asia and the Far East - Ad Hoc Panel of Experts on Pest, Disease and Weed Problems in Some Rainfed Crops 15 Sep, Bangkok (Thailand) Abst.

Duveiller, E. Garcia, A.I., 2000. Pathogenicity of Bipolaris sorokiniana isolates from wheat (roots, leaves and grains) in Mexico. Plant Pathol. 49, 235-242.

Emami, K., Hack, E., 2002. Conservation of XYN11A and XYN11B xylanase genes in Bipolaris sorghicola, Cochliobolus sativus, Cochliobolus heterostrophus and Cochliobolus spicifer. Curr. Microbiol. 45, 303-306.

Fuller, D.Q., 2003. Further evidence on the pre/history of sesame. Asian Agri-History. 7 (2), 127-137.

Goh, T., 1998. Generic distinction in the Hilmenthosporiumcomplex based on restriction analysis of the nuclear ribosomal RNA gene. Fungal Divers. 1, 109-113.

Hawksworth, D.L., Crous, P.W., Redhead, S.A., Reynolds, D.R., Samson, R.A., Seifert, K.A., Taylor, J.W., Wingfield, M.J., 2011. The Amsterdam declaration on fungal nomenclature. IMA Fungus. 2, 105-112.

Hobbs, P., Morris, M., 1996. Meeting South Asia's Future Food Requirements from Rice -Wheat Cropping Systems: Priority Issues Facing Researchers in the Post-Green Revolution Era. NRG Paper 96-01. D.F.; CIMMYT, Mexico, pp. 46

http: // www. ncbi. nlm. nih. Gov / BLAST. The sequences were analyzed using BLAST program (http://www.ncbi.nlm.nih.gov/BLAST) Sequences were aligned using Align Sequences Nucleotide BLAST.

Hyde, K., Chomnunti, P., Crous, P., Groenewald, J., Damm, U., Ko, T.W.K., Shivas, R., Summerell, B., Tan, Y., 2010 A case for re-inventory of Australia's plant pathogens. Persoonia Mol. Phylog. Evol. Fungi, 25, 50-60.

Inglis, P.W., Teixeira, E.A., Ribeiro, D.M., Valadares-Inglis, M.C., Tigano, M.S., Mello, S.C.M., 2001. Molecular markers for the characterization of Brazilian Cercospora caricis isolates. Curr. Microbiol. 42, 194-198.

Jain, K.L., Prabhu, A.S., 1976. Occurrence of chromogenic variant in Alternaria triticina. Ind. Phytopathol. 29 (1), 22-27.

Jayaramaiah, H., Siddaramaiah, A.L., Joshi, M.S., Habib, A.F., 1981. Varietal reactions of sesamum against Alternaria sesami (Kawamura) Mohanti and Beraha. Curr. Res. $10(1), 6-7$.

Jonsson, R., Säll, T., Bryngelsson, T., 2000. Genetic diversity for random amplified polymorphic DNA (RAPD) markers in two Swedish populations of Pyrenophora teres. Can. J. Plant Pathol. 22, 258-264.

KoKo, T.W., Stephenson, S.L., Bahkali, A.H., Hyde, K.D., 2011 From morphology to molecular biology: can we use sequence data to identify fungal endophytes? Fungal Divers. 36, 69-88.

Kolte, S.J., 1985. Disease of annual edible oil seed crops. Volume II: Rapeseed, Mustard, Safflower and Sesame diseases. CRC Press Inc, Boca Raton, FL. pp. 17-18.

Kumar, J., Schafer, P., Huckelhoven, R., Langen, G., Baltruschat, H., Stein, E., Nagarajan, S., Heinzkogel, K., 2002. Bipolaris sorokiniana, a cereal pathogen of 
global concern: cytological and molecular approaches towards better control. Mol. Plant Pathol., 3 (4), 185195.

Leisova, L., Minarikova, V., Kucera, L., Ovesna, J., 2005. Genetic diversity of Pyrenophora teres isolates as detected with AFLP analysis. J. Phytopathol., 153, 569-632.

Madrid, H., da Cunha, K.C., Gené, J., Dijksterhuis, J., Cano, J., Sutton, D.A., Guarro, J., Crous, P.W., 2014. Novel Curvularia species from clinical specimens. Persoonia, 33, 48-60.

Malaguti, G., Subw, L.J., Cchej, N., 1972. Alternaria sesamicola on sesame (S. indicum). Agron. Trop. Venez. 22 (1), 7580.

Manamgoda, D.S., Cai, L., Bahkali, A.H., Chukeatirote, E., Hyde, K.D., 2011. Cochliobolus: an overview and current status of species. Fungal Divers., 51, 3-42.

Manamgoda, D. S., Cai, L., McKenzie, E.H.C., Crous, P.W., Madrid, H., Chukeatirote, E., Shivas, R.G., Tan, Y.P., Hyde, K.D., 2012. A phylogenetic and taxonomic reevaluation of the Bipolaris-Cochliobolus - Curvularia complex. Fungal Divers., 56, 131-144.

Manamgoda, D.S., Rossman, A.Y., Castlebury, L.A., Chukeatirote, E., Hyde, K.D., 2015. A taxonomic and phylogenetic re-appraisal of the genus Curvularia (Pleosporaceae): human and plant pathogens. Phytotaxa. 212, 175-198.

Maraite, H., Zinno, D.I., Longree, H., Daumerie, V., Duveiller., E., 1998. Fungi associated with foliar blight of wheat in warmer areas. In: Duveiller, E., Dubin, H.J., Reeves, J. McNab, A., 1997. Proceeding of the International Workshop on Hilmenthosporium Diseases of Wheat: Spot blotch and Tan spot. (Eds.): CIMMYT, El Batan, Mexico, February, 9-14, pp. 293-300.

Mc Donald, D., 1964. Annual Report for the Institute for Agricultural Research, Samaru for the year, 1962-63.

Mendoza, L., Ajello, L., Taylor, J.W., 2001. The taxonomic status of Lacazia loboi and Rhinosporidium seeberi has been finally resolved with the use of molecular tools. Rev. Iberoam Micol. 18, 95-98.

Mikhailova, L.A., Gogoleva, S.G., Gultyaeva, E.I., 2002. The interactions of Bipolaris sorokiniana strains and wheat samples. Mikologiya-i-Fitopathologiya, 36 (2), 63-66.

Ojiambo, P.S., Narla, R.D., Ayiecho, P.Q., Nyabundi, J.O., 1998. Effect of infection level of sesame (Sesamum indicum L.) seeds by Alternaria sesami on severity of Alternaria leaf spot. Trop. Agric. Res. Ext. 1, 125-130.

Peever, T.L., Milgroom, M.G., 1994. Genetic structure of Pyrenophora teres populations determined with random amplified polymorphic DNA markers. Can. J. Bot. 72, 915-923.

Peltonen, S., Jalli, M., Kammiovirta, K., Karjalainen, R., 1996. Genetic variation in Drechslera teres populations as indicated by RAPD markers. Ann. Appl. Biol., 128, $465-477$.

Rashid, A.Q., 2005. Aggressiveness of Bipolaris sorokiniana in sprouting wheat seeds. J. Agric. Rural Dev. Gazipur. $3(1 / 2), 33-38$.

Rau, D., Brown, A.H.D., Brubaker, C.L., Attene, G., Balmas, V., Saba, E., Papa, R., 2003. Population genetic structure of Pyrenophora teres Drechs. the causal agent of net blotch in Sardinian landraces of barley (Hordeum vulgare L.). Theor. Appl. Genet., 106, 947959.

Sahani, P., Mahapatra, S.S., 2014. Chemical management of Alternaria leaf spot disease of sesame in Odisha. J. Plant Protc. Environ. 11 (2), 64-66.
Schoch, C.L., Seifert, K.A., Huhndorf, S., Robert, V., Spouge, J.L., Levesque, C.A., Chen, W., Bolchacova, E., Voigt, K., Crous, P.W., Miller, A.N., 2012. Nuclear ribosomal internal transcribed spacer (ITS) region as a universal DNA barcode marker for fungi. Proc. Natl. Acad. Sci. USA. 109, 6241-6246.

Serenius, M., 2006. Population structure of Pyrenophora teres, the causal agent of net blotch of barley. Doctoral Dissertation. PhD Thesis, Faculty of Agriculture and Forestry, University of Helsink, Finland.

Shekharappa, G., Patil, P.V., 2001. Field reaction of sesame genotypes to Alternaria sesami. Karnataka, J. Agric. Sci. 14 (4), 1103-1104.

Shoemaker, R.A., 1959. Nomenclature of Drechslera and Bipolaris, grass parasites segregated from 'Hilmenthosporium'. Can. J. Plant Pathol. 37, 879-887.

Simmons, E.G., 2004. Novel dematiaceous hyphomycetes. Stud. Mycol. 50, 109-118.

Sivanesan, A., 1987. Graminicolous Species of Bipolaris, Curvularia, Drechslera, Exserohilum and Their Teleomorphs. C.A.B. International, Wallingford.

Sivanesan, A., 1990. Mycosphaerella graminicola. CMI descriptions of pathogenic fungi and bacteria No. 986. Mycopathologia. 109, 51-53.

Sneath, P.H.A., Sokal, R.R., 1973. Numerical Taxonomy. Freeman Publisher, San Francisco, California.

Stielow, J.B., Lévesque, C.A., Seifert, K.A., Meyer, W., Iriny, L., Smits, D., et al. 2015. One fungus, which genes? Development and assessment of universal primers for potential secondary fungal DNA barcodes. Persoonia. 35, 242-263.

Tan, Y.P., Madrid, H., Crous, P.W., Shivas, R.G., 2014. Johnalcornia gen. Et. Comb. Nov. and nine new combinations in Curvularia based on molecular phylogenetic analysis. Australas Plant Pathol. 43, 589603.

Tigano-Milani, M.S., Honeycutt, R.J., Lacey, L.A., Assis, R., McClelland, M., Sobral, B.W.S., 1995a. Genetic variability of Paecilomyces fumosoroseus isolates revealed by molecular markers. J. Invertebr. Pathol., 65, 274-282.

Tigano-Milani, M.S., Samson, R.R., Martins, I., Sobral, B.W.S., 1995b. DNA markers for differentiating isolates of Paecilomyces lilacinus. J. Genet. Microbiol. 141, 239-245.

Udayanga, D., Liu, X., Mckenzie, E.H.C., Chukeatirote, E., Bahkali, A.H.A., Hyde, K.D., 2011. The genus Phomopsis: biology, applications, species concepts and names of common phytopathogens. Fungal Divers. 50, 189-225.

Valente, P., Ramos, J., Leoncini, O., 1999. Sequencing as a tool in yeast molecular taxonomy. Can. J. Microbiol. 45 (11), 949-958.

Verma, M.L., Naresh, M., Sangwan, M.S., 2005. Fungal and bacterial diseases of sesame. In: Saharan, G.S., Mehta, N., Sangwan, M.S., eds., Diseases of Oilseed Crops Indus Publishing, New Delhi, pp. 269-303.

White, T.J., Bruns, T., Lee, S., Taylor, J., 1990. Amplification and direct sequencing of the fungal ribosomal RNA genes for phylogenetics. In: Innis, M.A., Gelfand, D. H., Sninsky, I.I., White, T.I. eds., PCR Protocols: A Guide to Methods and Applications. Academic Press, Inc., London, 315-322.

Wu, H.L., Steffenson, B.J., Li, Y., Oleson, A.E., Zhong, S., 2003. Genetic variation for virulence and RFLP markers in Pyrenophora teres. Can. J. Plant. Pathol. 25, 82-90.

Yu, S.H., Mathur, S.B., Neergard, P., 1982. Taxonomy and pathogenicity of four seed borne species of Alternaria from sesame. Trans. Brit. Mycol. Soc. 78, 447-458. 


\title{
توصيف عزلات من الفطرين Bipolaris sorokiniana Alternaria sesame المزولة من نبات السمسم في مصر
}

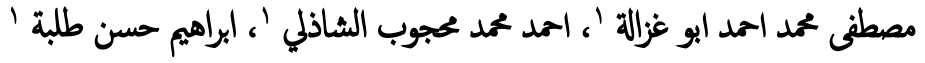

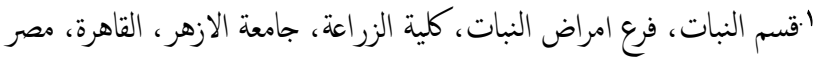

الملخص العربي

في هذه الدراسة تم عزل وتعريف فطري Bipolaris sorokiniana و Alternaria sesami وذلك بناء على على الفحص الميكروسكوبي وشكل المستعمرة واختبارات القدرة الامراضية. تم

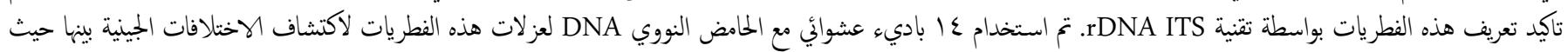

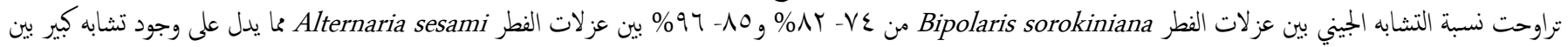

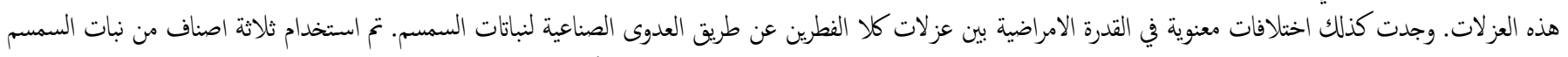

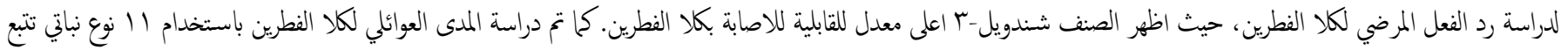

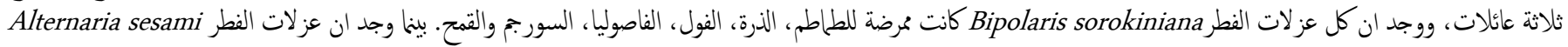

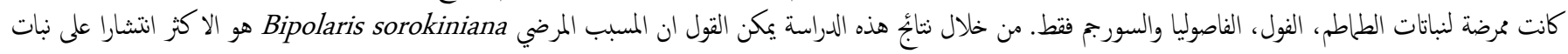

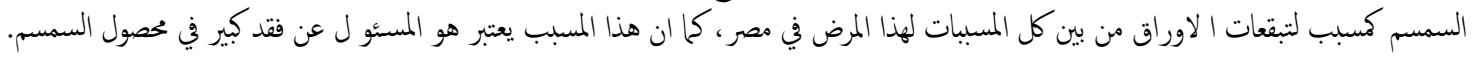

